\title{
Comparison of 0.052-Inch Coils vs Amplatzer Duct Occluder for Transcatheter Closure of Moderate to Large Patent Ductus Arteriosus
}

\author{
Ta Cheng Huang, MD*,**,†; Kuang-Jen Chien, MD*,**; Kai-Sheng Hsieh, MD*; \\ Chu-Chun Lin, MD*; Cheng-Liang Lee, MD, $\mathrm{PhD}^{*}, * *$
}

\begin{abstract}
Background Percutaneous device closure is now the widely accepted management technique for patent ductus arteriosus (PDA). In the present study, current practice of closing moderate to large PDA using the Amplatzer duct occluder (ADO) was compared with the previous experience using 0.052-inch coils.

Methods and Results From August 1997 to September 2006, 76 patients were selected for either 0.052-inch coils or ADO implantation. Selection criteria were a minimal diameter of $\geq 2.5 \mathrm{~mm}$ and angiographic type A, C, D or E. In group I, 21 patients received 0.052-inch coils in a multiple coil strategy for PDA closure. In group II, 55 patients underwent ADO device implantation. The age, weight, hemodynamics, minimal PDA diameter and shunt size were insignificantly different between groups. However, group I had a higher rate of failed implantation and device embolization, and the immediate and 24 -h closure rates $(38.9 \%$ vs $81.8 \%, \mathrm{P}<0.05 ; 72.3 \%$ vs $96.4 \%, \mathrm{P}<$ $0.05)$ favored group II.
\end{abstract}

Conclusions ADO implantation is safer and more effective than the 0.052-inch coil strategy for transcatheter closure of moderate to large PDA. (Circ J 2009; 73: 356-360)

Key Words: Amplatzer duct occluder; 0.052-inch coil; Patent ductus arteriosus

$\mathbf{T}$ ranscatheter closure of a patent ductus arteriosus (PDA) is currently a reliable alternative to surgery, even though challenging in the case of large complex ductal anatomy. Nonsurgical closure of PDA has become increasingly popular after its introduction by Portsmann et al in 1967! Since then various devices have been developed for transcatheter PDA closure, with coils being the most common method after the initial report by Cambier et al? Although it is a safe and effective treatment for small PDA, for large PDA, despite the technical improvements over the years, it is still a challenging task with a not negligible procedural failure rate and residual shunt. We previously studied the efficacy and safety of the 0.052-inch Gianturco coil (Cook, Bloomington, IN, USA) for closure of large PDA and complete closure of residual shunt with a multiple coils strategy, and the result was a moderate successful rate, but not without complications? With the introduction of the Amplatzer duct occluder (ADO) device (AGA Medical Corporation, Golden Valley, MN, USA), closure of large PDA has become safer and more effective.-6 In this report we compare the safety and efficacy of these therapeutic options in patients with moderate to large clinically symptomatic PDAs.

(Received May 13, 2008; revised manuscript received August 30, 2008; accepted September 4, 2008; released online December 8, 2008)

*Department of Paediatric Cardiology, Veterans General Hospital Kaohsiung, **Institute of Biomedical Sciences, National Sun Yat-Sen University, Kaohsiung and ${ }^{\dagger}$ National Yang-Ming University, Taipei, Taiwan

Mailing address: Cheng-Liang Lee, MD, PhD, Department of Paediatric Cardiology, Veterans General Hospital Kaohsiung, 386 Ta-Chung $1^{\text {st }} \mathrm{Rd}$, Kaohsiung 813, Taiwan. E-mail: tchuang@isca.vghks.gov.tw All rights are reserved to the Japanese Circulation Society. For permissions, please e-mail: cj@j-circ.or.jp

\section{Methods}

Between August 1997 and September 2006, 78 patients were selected for transcatheter closure of moderate to large PDA (minimal PDA diameter $\geq 0.25 \mathrm{~cm}$ ). Two patients were excluded after aortography documented the PDA as too large to close in 1 case and too small for percutaneous closure in the other case. Therefore, 76 patients underwent percutaneous closure of large PDA. The age at the time of procedure ranged from 21 days to 46 years (mean: 5.7 \pm 9.3 years) and the weight ranged from 3.3 to $62 \mathrm{~kg}$ (mean: $16.8 \pm 15.3 \mathrm{~kg}$ ). The minimum diameter of the PDA ranged from 2.5 to $8.0 \mathrm{~mm}$ (mean: $4.1 \pm 0.9 \mathrm{~mm}$ ). The pulmonary blood flow to systemic blood flow ratio obtained by the Fick method ranged from 1.5 to 4.8 , with a mean value of $2.4 \pm 0.5$. Twenty-one patients $(27 \%)$ were on medication to reduce cardiac preload. Between August 1997 and October 2002, 21 patients received at least one 0.052-inch coil and achieved complete closure with a multiple coil strategy for large PDA. In mid-2001 we started using the ADO and data from 55 patients were collected till September 2006. Based on PDA size and morphology, duct occlusion was achieved by 0.052 -inch Gianturco coil (21 patients, group I) or ADO (55 patients, group II). After informed consent from adult patients or the child's parents, cardiac catheterization was performed under heavy sedation for children and local anesthesia. All patients underwent right and left heart catheterization. The PDA closure protocol has been well described ${ }^{3-7}$ Briefly, after hemodynamic study and data collection, descending aortography in the right anterior oblique and lateral views was performed and the PDA shape and size were analyzed and classified according to Krichenko et al: ${ }^{4} 49$ patients had type A, 21 had type C, 1 had type D and 5 had type E. All patients had typical continuous murmur. 

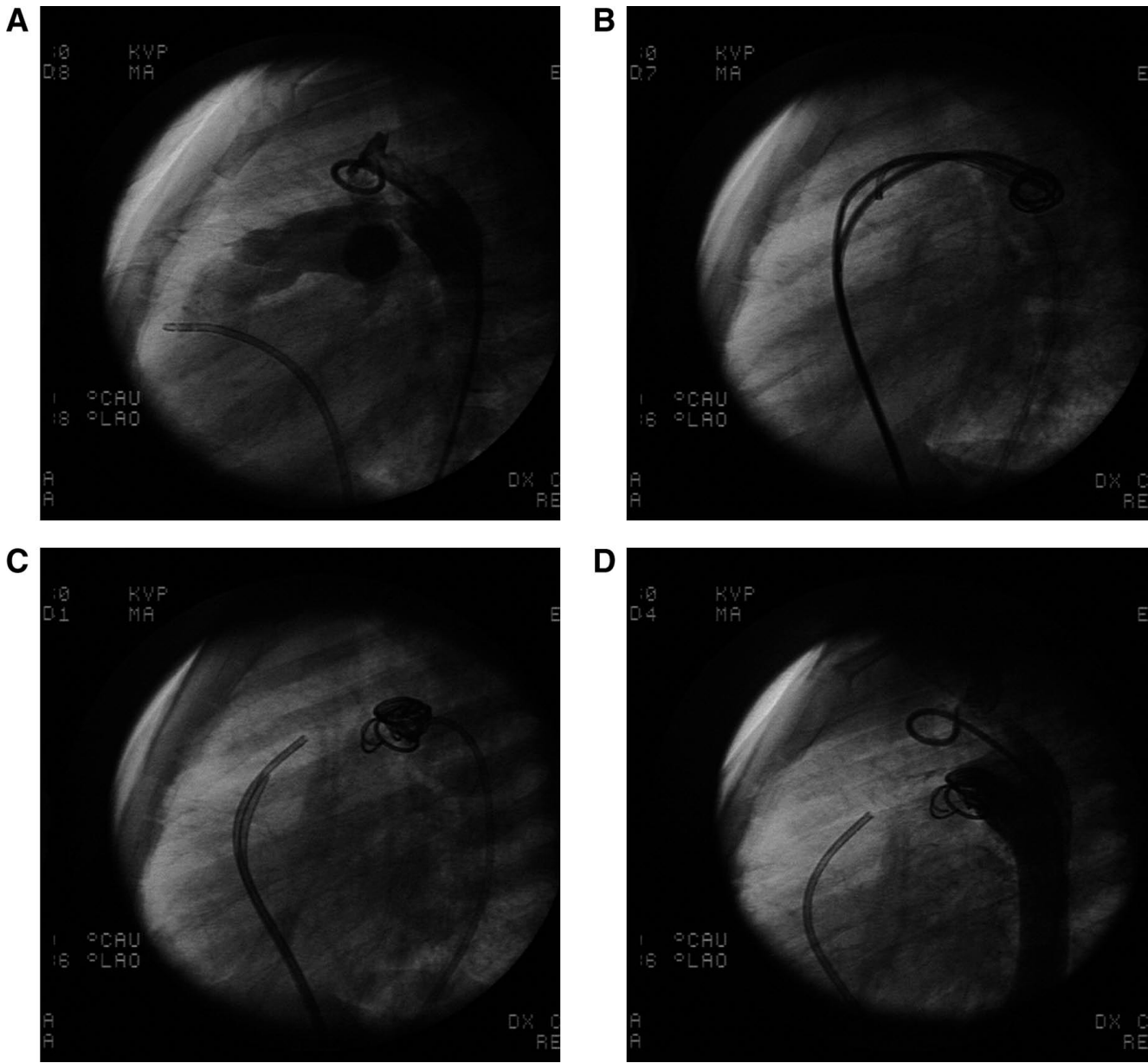

Fig 1. Closure of patent ductus arteriosus (PDA) by simultaneous implantation of $2 \times 0.052$-inch and $1 \times 0.038$-inch Gianturco coils. (A) Preclosure PDA angiographic appearance. (B) Simultaneous coil deployment from both the aortic and pulmonary sides. (C) Additional 0.038-inch coil deployed via arterial route. (D) Complete PDA occlusion at the angiographic control.
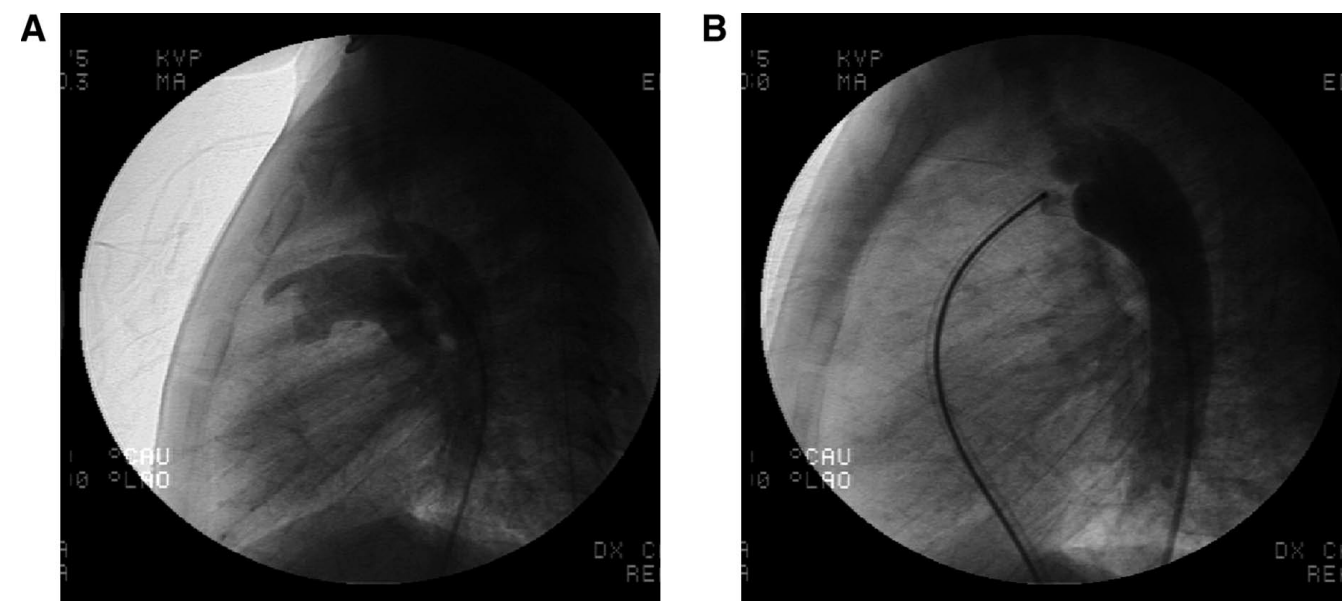

Fig 2. (A) Closure of a 3.8-mm, conical patent ductus arteriosus by implantation of a 9-PDA-005 (size 8/6) mm ADO device. (B) No residual shunt at the angiographic control.

In the coil method, a single coil was used for the first implantation and if necessary 2 coils were implanted simultaneously (Fig 1). We chose the coil diameter to be 2-2.5-fold wider than the narrowest duct diameter and long enough to produce 3-4 loops. During implantation, the Gianturco coils maintain their tightly wound loop size and configuration, and if necessary a second coil is used for shunt closure. Echocardiography and fluoroscopy are performed to ensure the coils are in situ and the PDA shunt closed. Color Doppler echocardiography (VingMed Ultrasound system Five, GE 
Table 1 Clinical Data of Patients Undergoing Transcatheter Closure of PDA

\begin{tabular}{lccc}
\hline \hline & Group I & Group II & Pvalue \\
\hline No. of patients $(n)$ & 21 & 55 & \\
Age (years) & $9.1 \pm 10.2(1.5-46)$ & $4.4 \pm 8.7(1$ month-3 years) & $>0.05$ \\
Weight $(\mathrm{kg})$ & $24.1 \pm 15.0$ & $14.1 \pm 15.3$ & $>0.05$ \\
Medication for CHF & 2 & 19 & $>0.05$ \\
Pulmonary artery systolic pressure $(\mathrm{mmHg})$ & $30.2 \pm 4.8$ & $31.5 \pm 8.9$ & $>0.05$ \\
Qp/Qs & $2.5 \pm 0.5(1.5-3.5)$ & $2.3 \pm 0.5(1.5-4.8)$ & $>0.05$ \\
Minimal PDA diameter $(\mathrm{mm})$ & $4.1 \pm 0.9$ & $3.9 \pm 1.0$ & $>0.05$ \\
Procedure time $($ min) & $98.1 \pm 38.2(52-129)$ & $64.7 \pm 41.3(43-132)$ & $<0.05$ \\
Fluoroscopy time $(\mathrm{min})$ & $26.9 \pm 22.4(14-44)$ & $21.4 \pm 16.8(11-24)$ & $>0.05$ \\
Angiographic duct type & Type A: 16, D: 1, E: 4 & Type A:33, C: 21, E: 1 & \\
\hline
\end{tabular}

Data are mean $\pm S D$.

$P D A$, patent ductus arteriosus; $Q p / Q s$, pulmonary to systemic flow ratio.

Table 2 Clinical Results of Patients Undergoing Transcatheter Closure of PDA According to the Therapeutic Options

\begin{tabular}{lccc}
\hline \hline & Group I & Group II & P value \\
\hline Device/patient & Gianturco coils $n=21$ & ADO deviceln $=55$ & \\
Fail implantation & 3 & 0 & $<0.05$ \\
Echocardiographic residual shunt after successful implantation & & & \\
Immediate & $11(61.1 \%)$ & $10(18.2 \%)$ & $<0.05$ \\
1 day after implantation & $5(27.7 \%)$ & $2(3.6 \%)$ & $<0.05$ \\
1 month after implantation & $1(5.5 \%)$ & 0 & $>0.05$ \\
6 months after implantation & $1(5.5 \%)$ & 0 & $>0.05$ \\
Device embolization & $3(16.6 \%)$ & 0 & $>0.05$ \\
Hemolysis & $2(11.1 \%)$ & 0 & $>0.05$ \\
\hline
\end{tabular}

ADO, Amplatzer duct occluder. Other abbreviation see in Table 1.

Corp, Stockton, CA, USA) is used to check for residual and if there is persistent flow with a diameter larger than $1 \mathrm{~mm}$, a coil with a diameter 1.5-2-fold times wider than the narrowest duct diameter is used. Closure of PDA was considered successful if no residual shunt or trivial residual shunt $(<1 \mathrm{~mm}$ color Doppler jet) was found by echocardiography $15 \mathrm{~min}$ after implantation.

For the ADO technique, we chose the device size to be $2 \mathrm{~mm}$ larger than the minimal duct diameter measured by aortography. The device was deployed via the right heart through the pulmonary artery (PA)-descending aorta route (Fig 2). The technique of transcatheter closure has been described in detail!-6 In brief, after a complete saturation and hemodynamic study, biplane anteroposterior and lateral descending aortography was performed to evaluate the size and anatomy of the PDA. A 0.038-inch exchange guidewire is placed across the ductus from the PA via an end-hole catheter. Over the wire, a 6,7 or $8 \mathrm{Fr}$ long sheath (AGA Medical Corporation) is introduced from the femoral vein through the duct into the aorta. An ADO at least $2 \mathrm{~mm}$ larger than the narrowest diameter of the duct is chosen. We open the disk in the distal thoracic aorta in order to avoid possible damage to the aortic wall by the protrusion of the small metal disk. Once in position, the disk is pulled gently against the orifice of the PDA and with gentle tension on the delivery cable, the sheath is pulled back to deploy the pulmonary end of the device. With the device still attached to the cable, transthoracic color Doppler echocardiography and descending aortography are performed to confirm proper device position and exclude left PA or aortic obstruction. Once in the optimal position, the ADO is released by counterclockwise rotation of the delivery cable. Repeat echocardiography is performed to check for residual shunt $15 \mathrm{~min}$ after the release of the ADO. Prophylactic cefazolin and gentamicin were routinely administered during the procedure. All patients were sent home 2 days after transcatheter PDA occlusion with no medication. Endocarditis prophylaxis was discontinued at the 6-month follow-up visit if the ductus was completely closed. Procedural and fluoroscopy time were calculated at the end of the procedure. Clinical and echocardiographic follow-up were routinely performed at discharge, after 1, 6, and 12 months, and then annually thereafter if any residual shunt persisted. PDA was considered fully occluded if no residual shunt was seen on echocardiography, and recanalization was considered to have occurred if any duct shunt was detected in a patient with a previously documented complete occlusion.

Results are expressed as mean $\pm \mathrm{SD}$; and range with median. Statistical analysis was performed using the unpaired Student's t-test and the Fisher exact test. Significance was defined as $\mathrm{P}<0.05$.

\section{Results}

Transcatheter closure was performed in all but 2 patients (97.7\%); in 1999, a 48-kg, 16-year-old girl was referred for PDA closure but she had a tubular PDA that measured approximately $6 \mathrm{~mm}$, which was judged as impossible for coil closure. The other exclusion was a baby aged 1-month-old, weighing $3.3 \mathrm{~kg}$ in severe congestive heart failure. Angiography at the time of intended PDA occlusion revealed an 8-mm tubular PDA, which was too large and unsuitable for closure with an 8/10-mm ADO because of the small aortic isthmus. She was also referred for surgical repair. Clinical, hemodynamic, and angiographic data at procedure of the remaining patients are listed in Table 1 . The results according to the therapeutic option are reported in Table 2. There were 3 patients in group I who had failed implantation of 
Table 3 Clinical Results of Occlusion of PDA $\geq 2.5 \mathrm{~mm}$ and $<4 \mathrm{~mm}$ With 0.052-Inch Coil or ADO

\begin{tabular}{lccc}
\hline \hline & Gianturco coils & ADO & Pvalue \\
\hline No. of patients $(n)$ & 9 & 36 & \\
Age (years) & $4.7 \pm 4.8$ & $2.4 \pm 4.7$ & $>0.05$ \\
Qp/Qs & $2.5 \pm 0.3$ & $2.3 \pm 0.4$ & $>0.05$ \\
Successful deployment & 8 & 36 & $N S$ \\
Complete occlusion & 8 & 36 & $N S$ \\
Migration & 1 & 0 & $N S$ \\
\hline
\end{tabular}

Data are mean $\pm S D$.

NS, not significant. Other abbreviations see in Tables 1,2.

coils. The first was a 55-kg, 20-year-old man who had coil embolization to the right PA and was referred for surgical removal and closure. Another $9.8-\mathrm{kg}, 10$-month-old infant had hemolysis and late coil migration to the left PA and was later referred for surgery. The last patient was a 3-yearold girl with coil embolization to the left PA. We retrieved the coil by a snare and she was referred for surgical closure on her family's decision. There was no significant difference in the age distribution of the 2 groups $(4.4 \pm 8.7$ vs $9.1 \pm 10.2$, $\mathrm{P}>0.05)$. Other parameters, including weight, PA pressure, PDA diameter, medications for heart failure and $\mathrm{Qp} / \mathrm{Qs}$, showed no significant difference between groups. In the group I patients, 37 coils [0.052-inch coils $(\mathrm{n}=28)$ and 0.038 inch coils $(n=9)]$ were used in 21 patients $(1$ coil in 7 patients, 2 coils in 12 patients, 3 coils in 2 patients). In group II patients, each patient received an ADO device (6/4 in 6 patients, $8 / 6$ in 39 patients, $10 / 8$ in 8 patients and 12/10 in 2 patients). Procedural time and fluoroscopic time in the ADO group were $64.7 \pm 41.3 \mathrm{~min}$ (range $43-132$ ) and $21.4 \pm$ $16.8 \mathrm{~min}$ (range 11-24; median $21 \mathrm{~min}$ ), respectively. Successful implantation of the device was achieved in $96.1 \%$ of patients at discharge. The multiple coil approach was significantly more time-consuming than ADO implantation $(98.1 \pm 38.2$ vs $64.7 \pm 41.3 \mathrm{~min}, \mathrm{P}<0.05)$ but without any significant difference in fluoroscopic time $(26.9 \pm 22.4$ vs $21.4 \pm$ $16.8 \mathrm{~min}, \mathrm{P}>0.05)$. The immediate and $24 \mathrm{~h}$ occlusion rates were significantly better in the ADO group than in the coil group $(81.8 \%$ vs $38.9 \%$ at $15 \mathrm{~min}$; $96.4 \%$ vs $72.3 \%$ after $24 \mathrm{~h} ; \mathrm{P}<0.05)$. However, the occlusion rate was not significantly different at 1-month and 6-month follow-up (100\% vs $94.5 \% ; 100 \%$ vs $94.5 \%, \mathrm{P}>0.05)$. Hemolysis occurred in 2 patients in group I: 1 patient received an extra coil and hemolysis improved; the other underwent surgery because of late migration of the coils after thrombolysis therapy for femoral artery thrombosis. Coil embolization to the peripheral PA occurred in 3 patients and 2 were retrieved. One coil was not able to be retrieved, but was not causing discomfort, and the patient underwent uneventful repeat coil implantation for PDA closure. Regarding device embolization and failure of implantation, statistical analysis favored the ADO group. Except for the 1 case of late migration, there were no late complications or PDA recanalizations during the midterm follow-up in either group. There was also no left PA stenosis or aortic isthmus flow abnormalities at follow-up pulse wave echo Doppler analysis.

We also compared the results of using 0.052-inch coils or the ADO device for PDAs $\geq 2.5 \mathrm{~mm}$ or $<4 \mathrm{~mm}$. The results showed no difference in the successful deployment and occlusion rates in our patient population; the complication of migration was also statistically not significant in this study (Table 3).

\section{Discussion}

Since the first study of percutaneous PDA closure using the Gianturco coil reported by Cambier et al in 1992 , nonsurgical closure of PDA has been widely accepted as an alternative to surgical closure. Though the results are encouraging in small PDA, it is still a challenging task for large PDA closure, with occasional procedural failures and residual shunt. The most challenging task is in small children with a moderate to large PDA $(\geq 2.5 \mathrm{~mm})$ because inappropriate implantation or migration of the coil to the pulmonary or peripheral systemic arteries can happen. Before the introduction of the ADO device, we used the large 0.052-inch coils combined with a multiple coil strategy for PDA closure,, 9 It is an effective method, but also revealed significant complications with hemolysis and/or embolization,10,11 which required longer hospital stay; even second catheterization for further coil placement. In our study, the failure rate was significant in the coil group $(16.6 \%$ vs $0 \% ; \mathrm{P}<0.05)$. Device embolization was also significantly different between the 2 groups $(\mathrm{P}<0.05)$, although hemolytic complications were not significantly different $(\mathrm{P}>0.05)$ (Table 2).

Many devices were developed for large PDA closure, including the Sideris buttoned device (Custom Medical Devices, Amarillo, TX, USA), or the Gianturco-Grifka Vascular Occlusion device (Cook Inc, Bloomington, IN, USA)!2,13 However, the results were not promising. Recently, the ADO device has proved to be highly effective in several studies,- 6 the implantation method is easy and has several favorable features, including a relatively small delivery sheath (6$8 \mathrm{Fr}$ ), a design that affords the possibility of retrieval and of repositioning before release of the occluder, and high rates of closure. In our study, the ADO method had a significantly higher closure rate immediately and at 1 day after implantation, also with lower complications (Table 2). Consequently, we believe the ADO has definite advantages over multiple 0.052-inch coils for closing large PDAs. We also found the multiple coils approach more time-consuming with a significantly prolonged procedure time (Table 1$)(\mathrm{P}<0.05)$. The multiple coil approach is more technically challenging and has a not negligible incidence of procedural failures and complications. Accordingly, we believe the ADO device approach is the first option for closure of moderate to large PDA, whenever the local anatomy and PDA shape allow its use.

There are some reports regarding the use of 0.052-inch coils for PDA occlusion. In a study by Tomita et al, they also used the 0.052-inch coil and complete closure with other smaller sized coils, and their results showed a successful outcome for PDA around $3 \mathrm{~mm}$ in size was significant differently than that for a PDA larger than $4 \mathrm{~mm} \cdot{ }^{14} \mathrm{We}$ analyzed our data from selected patients with a PDA $\geq 2.5 \mathrm{~mm}$ or $<4 \mathrm{~mm}$, 
and there were no significant differences in successful closure rate or complications between 0.052-inch coils and the ADO device (Table 3). However, there was 1 case of a migrating coil, which was retrieved surgically. Kobayashi et al also reported that coil migration in children was not uncommon $1^{15}$ Though we did not have any cases of hemolysis using coil occlusion for PDA $\geq 2.5 \mathrm{~mm}$ or $<4 \mathrm{~mm}$, the complication of hemolysis was more frequent in the coil group and is an unacceptable outcome. Hence, the use of 0.052inch coils for closure of moderate to large PDA should be carefully considered on the basis of the angiographic findings and the availability of an experienced interventionist.

Overall, the PDA occlusion rate in this study was as high as $96.1 \%$ after 1 month and over the mid-term follow-up. After the procedure, a trend toward an earlier complete PDA closure after ADO implantation was recorded, with a significant difference between the groups (Table 2). Though, despite the multiple coil approach being cheaper than the ADO device approach, ${ }^{16}$ we found it appropriate to use the ADO approach for large PDA closure. However, 0.052-inch coils might still be used for PDA around $3 \mathrm{~mm}$ and appropriate morphology. Further study should be conducted to clarify the safety and efficacy of large PDA closure. In conclusion, introduction of the ADO device decreased eventful deployment during percutaneous occlusion of PDA $\geq 2.5 \mathrm{~mm}$, and contributed to better outcomes of occlusion of PDA $\geq 2.5 \mathrm{~mm}$.

\section{References}

1. Porstmann W, Wierny L, Warnke H. Closure of persistent ductus arteriosus without thoracotomy. Ger Med Mon 1967; 12: 259-261.

2. Cambier PA, Kirby WC, Wortham DC, Moore JW. Percutaneous closure of the small (less than $2.5 \mathrm{~mm}$ ) patent ductus arteriosus using coil embolization. Am J Cardiol 1992; 69: 815-816.

3. Huang TC, Hsieh KS, Lee CL, Lin CC. Safety and efficacy of using 0.052 -inch Gianturco coil for closure of large $(>$ or $=4 \mathrm{~mm})$ patent ductus arteriosus. J Invasive Cardiol 2002; 14: 173-177.

4. Masura J, Walsh KP, Thanopoulous B, Chan C, Bass J, Goussous Y, et al. Catheter closure of moderate- to large-sized patent ductus arteriosus using the new Amplatzer duct occluder: Immediate and shortterm results. J Am Coll Cardiol 1998; 31: 878-882.

5. Bilkis AA, Alwi M, Hasri S, Haifa AL, Geetha K, Rehman MA, et al. The Amplatzer duct occluder: Experience in 209 patients. $J$ Am Coll Cardiol 2001; 37: 258-261.

6. Pass RH, Hijazi Z, Hsu DT, Lewis V, Hellenbrand WE. Multicenter USA Amplatzer patent ductus arteriosus occlusion device trial: Initial and one-year results. J Am Coll Cardiol 2004; 44: 513-519.

7. Hijazi ZM, Geggel RL. Transcatheter closure of large patent ductus arteriosus $(>$ or $=4 \mathrm{~mm})$ with multiple Gianturco coils: Immediate and mid-term results. Heart 1996; 76: 536-540.

8. Krichenko A, Benson LN, Burrows P, Moes CAF, McLaughlin P, Freedom RM. Angiographic classification of the isolated, persistently patent ductus arteriosus and implications for percutaneous catheter occlusion. Am J Cardiol 1989; 63: 877-880.

9. Tomita H, Ono Y, Miyazaki A, Tanaka T, Kimura K, Echigo S. Transcatheter occlusion of patent ductus arteriosus using a 0.052inch coil. Jpn Circ J 2000; 64: 520-523.

10. Uzun O, Veldtman GR, Dickinson DF, Parsons JM, Blackburn ME, Gibbs JL. Haemolysis following implantation of duct occlusion coils. Heart 1999; 81: 160-161.

11. Huang TC, Hsieh KS, Lee CL. Late coil migration due to thrombolysis after successful implantation of a coil for persistent ductus arteriosus. Catheter Cardiovasc Interv 2000; 50: 334-336.

12. Sideris EB, Rao PS, Zamora R. The Sideris buttoned devices for transcatheter closure of patent ductus arteriosus. J Interv Cardiol 2001; 14: 239-246.

13. Grifka RG, Vincent JA, Nihill MR, Ing FF, Mullins CE. Transcatheter patent ductus arteriosus closure in an infant using the Gianturco-Grifka Vascular Occlusion Device. Am J Cardiol 1996; 78: 721 - 723.

14. Tomita H, Takamuro M, Fuse S, Horita N, Hatakeyama K, Tsutsumi H, et al. Coil occlusion of patent ductus arteriosus. Circ J 2006; 70: $28-30$.

15. Kobayashi T, Tomita H, Fuse S, Takamuro M, Hatakeyama K, Horita $\mathrm{N}$, et al. Coil occlusion for patent ductus arteriosus larger than $3 \mathrm{~mm}$. Circ J 2005; 69: 1271 - 1274 .

16. Santoro G, Bigazzi MC, Palladino MT, Russo MG, Carrozza M, Calabrò R. Comparison of percutaneous closure of large patent ductus arteriosus by multiple coils versus the Amplatzer duct occluder device. Am J Cardiol 2004; 94: 252-255. 